\title{
Trajectory Analysis and Risk Evaluation of Dangerous Rock Mass Instability of an Overhang Slope, Southwest of China
}

\author{
Wen-lian Liu, ${ }^{1,2}$ Jia-xing Dong $\mathbb{D}^{3}{ }^{3}$ Han-hua $X u,{ }^{1,2}$ Su-gang Sui, ${ }^{1,2}$ Run-xue Yang, ${ }^{3}$ \\ and Lun-shun Zhou ${ }^{3}$ \\ ${ }^{1}$ Kunming Prospecting Design Institute of China Nonferrous Metals Industry Co., Ltd., Kunming, Yunnan 650051, China \\ ${ }^{2}$ Yunnan Key Laboratory of Geotechnical Engineering and Geohazards, Kunming, Yunnan 650051, China \\ ${ }^{3}$ Faculty of Electric Power Engineering, Kunming University of Science and Technology, Kunming, Yunnan 650500, China
}

Correspondence should be addressed to Jia-xing Dong; dong1986@kust.edu.cn

Received 23 April 2021; Accepted 28 May 2021; Published 24 June 2021

Academic Editor: Faming Huang

Copyright (C) 2021 Wen-lian Liu et al. This is an open access article distributed under the Creative Commons Attribution License, which permits unrestricted use, distribution, and reproduction in any medium, provided the original work is properly cited.

Analysis of the movement trajectory and risk assessment of the high-slope dangerous rock mass collapse are of great significance for preventing and controlling the geological disasters of collapse. This study firstly takes the dangerous rock mass of the high slope in Pu'erdu Town, Yanjin County, Zhaotong City, Yunnan Province, as the research object, calculates and analyzes the trajectory of collapse movement of several groups of dangerous rock mass with great threat, and RocFall are used to carry out numerical simulation analysis and verification. Secondly, the risk and vulnerability of the dangerous rock mass in the study area are analyzed, and the risk evaluation is carried out through the risk evaluation matrix to clearly define the risk level. Results show that if the dangerous rock mass collapses, the horizontal movement distance was approximately 53-88 $\mathrm{m}$, and the maximum bounce height of the platform was approximately $3-18 \mathrm{~m}$, which will seriously threaten the life and property safety of residents. There is little difference between the simulation of the collapse of dangerous rock mass by RocFall software and the calculation result of the formula. Although RocFall software is more intuitive and can be directly compared with charts, software cannot completely simulate the actual situation, and it is only suggested as a reference from design rather than a basis of design. The result of risk evaluation shows that there are 2 high-risk dangerous rocks, 3 medium-risk dangerous rocks, and 1 low-risk dangerous rock in this area. It is suggested that a reasonable and scientific engineering treatment scheme should be put forward as soon as possible in combination with the collapse trajectory of the collapsing movement.

\section{Introduction}

Pu'er Town, Yanjin County, Zhaotong City, Yunnan Province, is an area where the geological hazards are most developed in Yunnan Province, especially with landslides, collapses, debris flow, etc. For instance, on July 18, 2005, a landslide occurred in the residential area of the Pu'er branch of Yanjin Vocational Middle School. The crack was more than 30 meters long and the crack width was about $30 \mathrm{~cm}$. The overall downward trend involved an area of more than 0.7 acres, which directly threatened 22 residents, two government agencies, 10 people in the family planning station, and a middle school, totally about 35 million yuan in property threatened. On August 29, 2007, a collapse occurred above Shijie Community of Tiaoqiao, Pu'er Town, and a house was smashed, the stone weighing about 2 tons, endangering 21 people in 8 households and causing a direct economic loss of 800,000 yuan. On August 10, 2008, hit by heavy rain, a collapse occurred on the left side of Guanyinyan (Bench Rock) in Tiaoqiao Community, Pu'er Town, accompanied by debris flow, resulting in varying degrees of damage to 13 households; one person was injured, and 15 pigs washed away. The direct economic loss is more than 2 million yuan. The frequent occurrence of geological hazards threatens the life and property safety of the people in Pu'er Town, causing huge losses to the national economy and severely restricting the development of the local economy. Therefore, it is very urgent and necessary to analyze the 
trajectory of the collapse of the dangerous rock mass in the disaster area and evaluate the risk to prevent the geological disaster from further causing casualties and property losses.

At present, the analysis methods of the falling path trajectory of the dangerous rock mass mainly include field test, empirical discrimination, and theoretical calculations. For example, the prediction formula for falling rock movement trajectory proposed by Bobbert et al. [1] and Dorren [2] has proposed the DOA model (reach angle model) of Angle and the shadow cone model (shallow angle model). Cui et al. [3], through the field test, obtained the overall flat, angle formulas for calculating local change linear slope rolling speed, and then estimated the speed of movement of the rolling stones and impact energy. $\mathrm{Gu} \mathrm{He}$ and Wang [4] studied the analytical method of rockfall trajectory prediction, indoor rockfall experiment, and field experiment. Yang and Zhou [5] considered the influence of rockfall shape of rockfall trajectory and approximated rockfall to an ellipse; according to the common forms of rockfall motion, a theoretical method of calculation and prediction of rockfall trajectory was proposed. Based on the three stages of the whole process of rockfall movement, $\mathrm{Fu}$ et al. [6] obtained the velocity calculation formula for each stage by using the segmented cycle algorithm, established the model, and applied the theoretical formula for the prediction of rockfall movement trajectory. Cheng and Su [7] studied nearly 400 collapsing rock profiles in the Wenchuan earthquake through statistical analysis and obtained the movement characteristics and damage ranged parameters of the rock. RocFall software appeared with the development of computer technology, which can be used to assess the risk of a rockfall by two-dimensional statistical analysis [8]. Ye et al. [9] proposed a three-dimensional prediction method of rockfall trajectory combined with the characteristics of geotechnical materials. Qin et al. [10] proposed a threedimensional analysis method of rockfall trajectory with the arbitrary shape of geotechnical slope; this method established rockfall and slope model with arbitrary shape, established rockfall motion equation according to the contact search algorithm and contact collision model between rockfall and slope, and simulated the three-dimensional motion trajectory of rockfall along a slope; the gap between the prediction results and the actual situation is narrowed. At present, despite the emergence of new methods, RocFall software is still most widely used. Based on RocFall software, many scholars have studied the kinetic energy, velocity, and bounce height envelope of the rockfall on the slope, the position of the endpoint of the rockfall rolling, the kinetic energy along the slope line, the velocity, the bounce height distribution, etc., which provide a reference for actual engineering [11-21].

Many institutions and scholars have put forward various definitions of geological hazard risks [22]. For example, Zhang [23], based on summarizing the risk assessment experience of developed countries and Hong Kong, China, put forward a basic concept of regional risk evaluation of geological hazards. RenQin [24] proposed to use the "product function" of hazard, vulnerability, and exposure to calculate risk. Yuan and Fang [25] proposed to evaluate the risk and hazard risks matrix and take the Yan'an Baota District in Shaanxi as an example to conduct geological hazards risk evaluation research and exploration.

Based on the analysis of the stability of the dangerous rock mass in the treatment area, this paper conducts a study on the prediction of the trajectory of the dangerous rock mass collapse and verifies it by numerical simulation through RocFall. By judging the hazard and vulnerability of the dangerous rock mass, the risk assessment matrix is used to evaluate the risk to clarify the risk level.

\section{Project Description}

Pu'erdu Town is located in the northwest of Yanjin County, Zhaotong City, Yunnan Province, about $20 \mathrm{~km}$ away from Yanjin County and $140 \mathrm{~km}$ away from Zhaotong City. The town covers an area of $234 \mathrm{~km}^{2}$ and has a population of about 60,000 . The topography and geomorphology conditions in the treatment area are very complex, which mainly manifested as flowing water geomorphology controlled by geological structures, the basic geomorphic units are alpines and valleys, and there are also gentle slope landforms developed along with the sedimentary rock layer. The lowest elevation within $4 \mathrm{~km}^{2}$ with Pu'er Town as the center is $355 \mathrm{~m}$ at the confluence of Chuansi River and Guan River, and the highest elevation is $699 \mathrm{~m}$ about $1 \mathrm{~km}$ northwest of Pu'er Town. The valley in the area is deep, mainly represented by $\mathrm{V}$-shaped river valleys, and the slopes of the valleys are steep, generally above $30^{\circ}$. Pu'erdu Town has been affected by river erosion for a long time, the terrain is steep and the ravines crisscross, which is a typical mountainous terrain. The geographic location of the study area is shown in Figure 1.

In this paper, we selected six dangerous rock masses $\mathrm{W} 1$, W2, W3, W4, W5, and W6 in the control area for study. The plane distribution of each dangerous rock mass is shown in Figure 2, the field photos are shown in Figure 3, and joints developed in the dangerous rock mass are shown in Table 1. The characteristics of dangerous rock points and their descriptions are shown in Table 2.

\section{Trajectory Analysis of Collapse Failure of Dangerous Rock Mass}

3.1. Theoretical. The analysis methods of the falling path of dangerous rock can be basically classified into four categories: field test, empirical discrimination, theoretical calculation, and numerical simulation. The falling rock is simplified as a sphere or particle, and here falling rock is simplified as a sphere in the theoretical calculation [26]. The results show that only when the slope is less than a certain critical value (about $12^{\circ}$ ) with the increase in slope, it can be shown as sliding, rolling, jumping, and free cave, and part or all of it can be accumulated at the foot of slope or valley [27]. When the slope of the avalanche is between $12^{\circ}$ and $45^{\circ}$, it will roll; when the slope is between $45^{\circ}$ and $76^{\circ}$, it will roll and jump; and if the slope is greater than $76^{\circ}$, the avalanche will perform a free-fall motion. The falling angle is shown in Figure 4(a). 
(a)

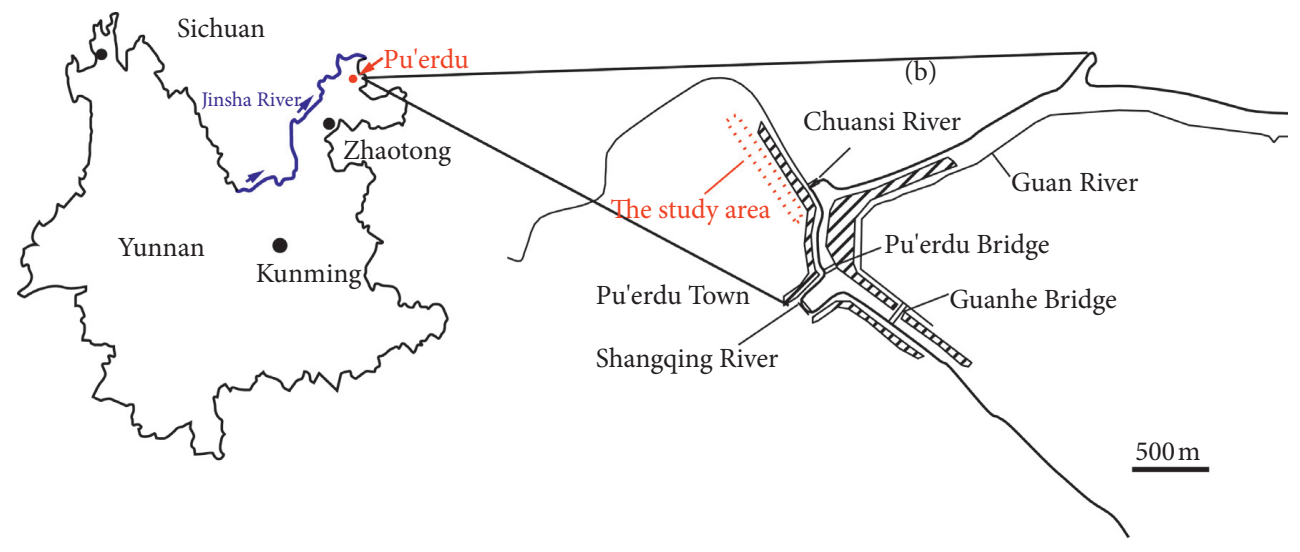

FIGURE 1: Geographical location of the study area.

Different types of dangerous rock blocks are unstable, and their collapse motion characteristics are different. The toppling dangerous rock mass is disintegrated at the foot of the cliff as the contact point and rolls down along the lower slope of $25^{\circ} \sim 40^{\circ}$, and the initial rolling velocity is small. The instability of falling dangerous rock mass all starts to fall from the upper or top of the cliff at about $80^{\circ}$, mainly due to the rotational fall of massive dangerous rock mass, rolls, and jumps on the lower slope at a high initial velocity until it stops. Through the investigation of the collapse block, the collapse distance of the dangerous rock in the exploration area is restricted by the terrain, and the shape of the block is similar to the dangerous rock block in the cliff zone.

Prediction and analysis of the movement distance of dangerous rock mass: as shown in Figure 4(b), when the falling rock falls on the slope surface for the first time, the energy changes due to collision, and part of the energy is consumed in the collision process.

According to the law of conservation of kinetic energy,

$$
g \cdot h=\frac{1}{2} m V^{2}
$$

where $g$ is the acceleration of gravity, $h$ is the height of the object from the reference plane, $m$ is the mass of the object, and $V$ is the velocity of the object.

According to the above equation, the velocity $V$ before the falling rock collision can be calculated. $V_{n}$ (normal velocity) and $V_{t}$ (tangential velocity) after the collision can be calculated by the following formula:

$$
\begin{aligned}
& V_{t}=V \cdot \cos \beta, \\
& V_{n}=V \cdot \sin \beta,
\end{aligned}
$$

where $V_{t}$ is the subvelocity of $V$ perpendicular to the slope $(\mathrm{m} / \mathrm{s}), V_{n}$ is the subvelocity of $V$ parallel to the slope $(\mathrm{m} / \mathrm{s}), \beta$ $\left({ }^{\circ}\right)$ is the angle between $V_{t}$ and $V$, and its value can be obtained according to the terrain contour.

3.2. Analysis of the Motion Trajectory of Dangerous Rock Mass. The terrain in the survey area has a steep slope and hard rock. After the collapse of the dangerous rock mass, except along the joint surface and bedding plane, most of the rock blocks are maintained well, forming rock blocks of different sizes, and the rock blocks will jump and roll along the hillside when they are unstable, which has strong impact damage ability, with the schematic diagram of collapse damage movement of dangerous rock mass (Figure 4(b)), it can be seen that after the collapse of dangerous rock mass, movement way of the rock mass is mainly rollingand jumping down. Taking the geological section of dangerous rock mass W1 as an example, as shown in Figure 5, the normal collision between falling rock and a loose layer of the slope between the 4 and 3 section of the W1 dangerous falling rock path can be considered as the core plastic collision, so $V n=0$. In the tangential collision, the loss rate is $10 \%$.

The kinetic energy of the first impact of the falling rock on the slope and its continuous motion is $0.5 \mathrm{~m}\left(0.9 \mathrm{~V}_{t}\right)^{2}$. The continuous movement towards falling rock on the slope is a comprehensive form of rolling and sliding, and for the convenience of calculation, it can be simplified to the comprehensive friction motion along the slope. According to the principle of function, the potential energy change of the falling rock is equal to the kinetic energy change and the work done to overcome friction:

$$
\sum m g \cdot \Delta h_{i}=\frac{1}{2} m\left(V_{i}^{2}-V_{t}^{2}\right)+\sum m g \cos a_{i} \cdot \operatorname{tg} \Phi_{r} \cdot L_{i}
$$

where $V i$ is the velocity of falling rock at any position on the slope surface $(\mathrm{m} / \mathrm{s})$, ai is the average slope $\left(^{\circ}\right)$ of each straight line section, $\Delta \mathrm{h}_{\mathrm{i}}$ is the vertical height of the slope of each straight line segment $(\mathrm{m}), \Phi_{r}$ is the comprehensive friction angle between the falling rock and the slope $\left({ }^{\circ}\right)$, and $L_{i}$ is the length of each slope $(\mathrm{m})$.

3.3. Calculation of Movement Distance. Since the cliff slope where the dangerous rock mass is located is greater than $76^{\circ}$, it can be considered that the dangerous rock is in free-fall motion during the fall. According to the law of conservation of kinetic energy, all the potential energy of the dangerous 


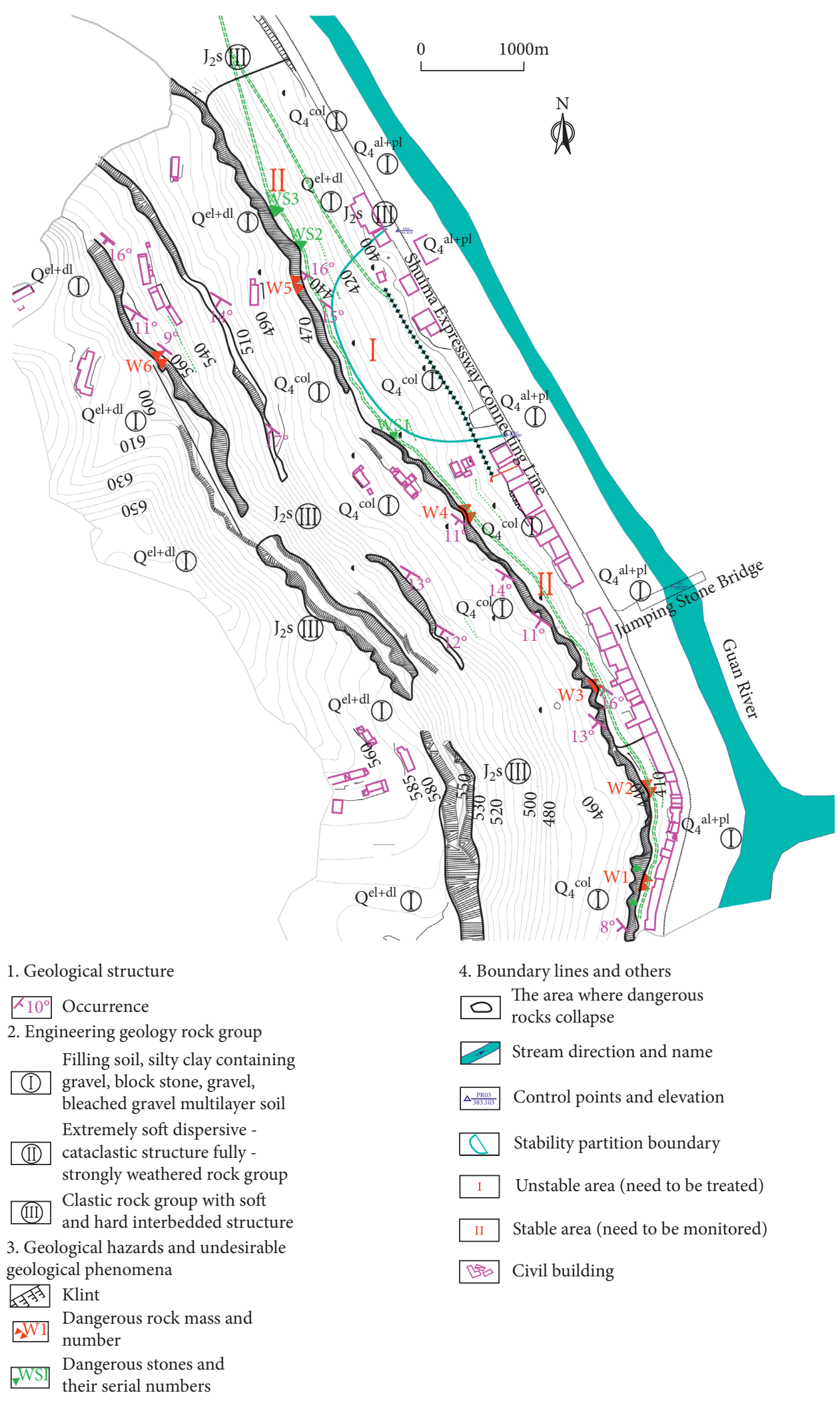

FIgURE 2: Plane distribution of dangerous rock mass.

rock mass is converted into kinetic energy immediately before the collision with the next slope section (without considering the air resistance). The maximum horizontal movement distance to the dangerous rock mass can be calculated by the above formula. The calculation results are shown in Table 3. 


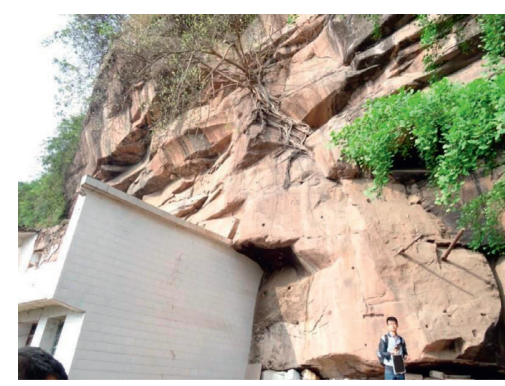

(a)

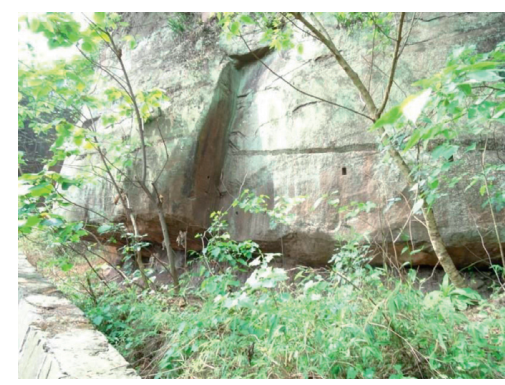

(d)

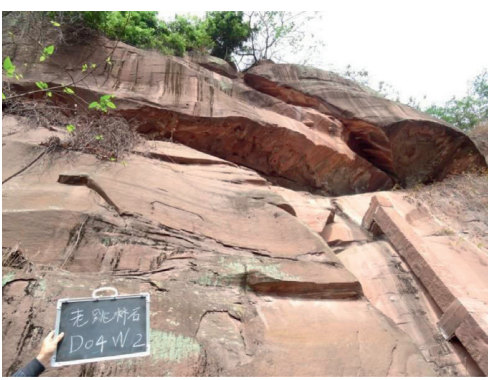

(b)

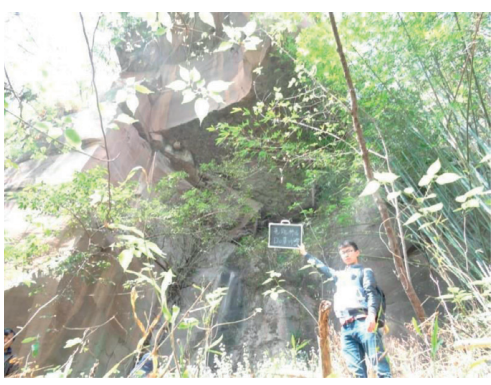

(e)

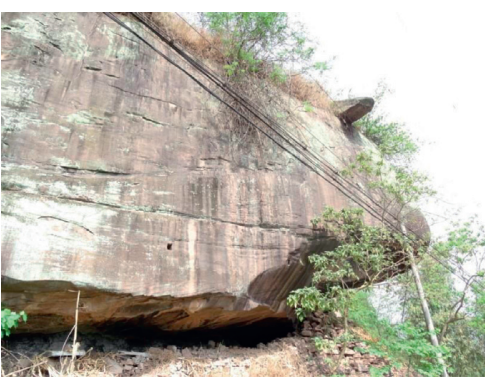

(c)

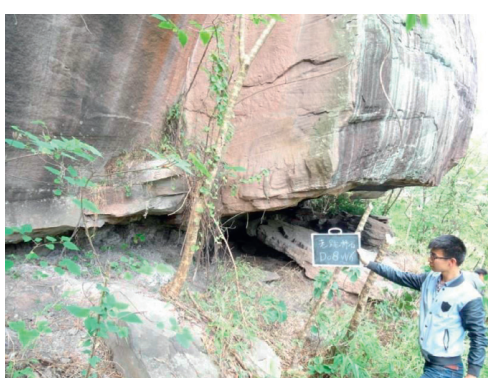

(f)

FIgURE 3: Field map of the investigated dangerous rock mass: (a) W1, (b) W2, (c) W3, (d) W4, (e) W5, and (f) W6, respectively.

TABle 1: Main joint developed in the dangerous rock mass.

\begin{tabular}{llccccc}
\hline \multirow{2}{*}{$\begin{array}{c}\text { Joint } \\
\text { Dangerous rock mass }\end{array}$} & \multicolumn{2}{c}{ Attitude } & Frequency (bar/m) & Strike extension length (m) & Tendency extension length (m) \\
\hline \multirow{2}{*}{$\mathrm{W} 1$} & $\mathrm{D} 1$ & $\mathrm{~N} 45^{\circ} \mathrm{E}$ & $89^{\circ}$ & $1 / 4 \sim 5$ & $18 \sim 20$ & $5 \sim 6$ \\
& $\mathrm{~J} 2$ & $\mathrm{~S} 80^{\circ} \mathrm{E}$ & $86^{\circ}$ & $1 / 18 \sim 20$ & $4 \sim 5$ & $15 \sim 20$ \\
\hline \multirow{2}{*}{$\mathrm{W} 2$} & $\mathrm{~J} 1$ & $\mathrm{~N} 80^{\circ} \mathrm{E}$ & $89^{\circ}$ & $1 / 8 \sim 10$ & 10 & $10 \sim 14$ \\
& $\mathrm{~J} 2$ & $\mathrm{~S} 10^{\circ} \mathrm{E}$ & $71^{\circ}$ & $1 / 23$ & 8 & $20 \sim 23$ \\
\hline \multirow{2}{*}{$\mathrm{W} 3$} & $\mathrm{~J} 1$ & $\mathrm{~N} 45^{\circ} \mathrm{E}$ & $80^{\circ}$ & $1 / 7 \sim 8$ & $7 \sim 8$ & $15 \sim 25$ \\
& $\mathrm{~J} 2$ & $\mathrm{~S} 70^{\circ} \mathrm{E}$ & $85^{\circ}$ & $1 / 10$ & $5 \sim 8$ & $10 \sim 15$ \\
\multirow{2}{*}{$\mathrm{W} 4$} & $\mathrm{~J} 1$ & $\mathrm{~N} 50^{\circ} \mathrm{E}$ & $87^{\circ}$ & $1 / 5 \sim 8$ & $14 \sim 16$ \\
& $\mathrm{~J} 2$ & $\mathrm{~S} 80^{\circ} \mathrm{E}$ & $86^{\circ}$ & $3 / 20$ & $6 \sim 8$ & $18 \sim 20$ \\
\multirow{2}{*}{$\mathrm{W} 5$} & $\mathrm{~J} 1$ & $\mathrm{~N} 35^{\circ} \mathrm{E}$ & $83^{\circ}$ & $1 / 6 \sim 8$ & $20 \sim 25$ & $10 \sim 15$ \\
\hline \multirow{2}{*}{$\mathrm{W} 6$} & $\mathrm{~J} 2$ & $\mathrm{~S} 35^{\circ} \mathrm{E}$ & $72^{\circ}$ & $1 / 20 \sim 25$ & $6 \sim 8$ & $10 \sim 15$ \\
& $\mathrm{~J} 1$ & $\mathrm{~N} 70^{\circ} \mathrm{E}$ & $74^{\circ}$ & $1 / 5 \sim 6$ & $8 \sim 10$ & $14 \sim 16$ \\
\hline
\end{tabular}

3.4. Bouncing Calculation. In this article, we only calculated the bounce height of W1, W2, W3, and W4, and the formula used is as follows.

Reflection speed after hitting the platform:

$$
V_{0}=(1-\lambda) V_{R} \cdot \frac{\cos \gamma}{\sin \gamma}
$$

The maximum height of the first bounce of the rock $h_{\text {max }}$ :

$$
h_{\max }=\frac{V_{0}^{2}}{2 g} \sin ^{2} \gamma .
$$

Total height of rock jumping:

$$
h=h_{s}+h_{\max },
$$

where $\lambda$ is the coefficient of friction when hitting the platform, $V_{R}$ is the velocity after hitting the platform, $\gamma$ is the reflection angle after hitting the platform, and $h_{s}$ is the safe value of jump height (generally $0.5 \sim 1.0$ ). The calculation results are shown in Table 4.

\section{The Numerical Simulation Verification Based on RocFall}

4.1. RocFall Software Introduction. RocFall is statistical analysis software used to evaluate the risk of falling rocks on 
TABLE 2: Characteristics of dangerous rock spots and economic losses caused by disasters.

\begin{tabular}{|c|c|c|c|c|c|}
\hline Category & $\begin{array}{l}\text { Destruction } \\
\text { mode }\end{array}$ & $\begin{array}{l}\text { Volume } \\
\left(\mathrm{m}^{3}\right)\end{array}$ & Stable state & Threat object & Economic loss \\
\hline W1 & Falling & 654 & Under stable & $\begin{array}{c}\text { People, houses, } \\
\text { highways, engineering } \\
\text { facilities }\end{array}$ & $\begin{array}{l}\text { Located above the concentration of residential houses, it } \\
\text { seriously threatens the safety of life and property, and the } \\
\text { economic loss caused by instability is huge }\end{array}$ \\
\hline W2 & Toppling & 4323 & $\begin{array}{l}\text { Basically } \\
\text { stable }\end{array}$ & $\begin{array}{l}\text { People, houses, } \\
\text { highways, engineering } \\
\text { facilities }\end{array}$ & $\begin{array}{l}\text { Located above the concentration of residential houses, it } \\
\text { seriously threatens the safety of life and property, and the } \\
\text { economic loss caused by instability is huge }\end{array}$ \\
\hline W3 & Falling & 280 & Unstable & $\begin{array}{l}\text { People, houses, } \\
\text { highways, engineering } \\
\text { facilities }\end{array}$ & $\begin{array}{l}\text { Located above the concentration of residential houses, it } \\
\text { seriously threatens the safety of life and property, and the } \\
\text { economic loss caused by instability is huge }\end{array}$ \\
\hline W4 & Falling & 2448 & Understable & $\begin{array}{l}\text { People, houses, } \\
\text { highways, engineering } \\
\text { facilities }\end{array}$ & $\begin{array}{l}\text { There are fewer houses under the dangerous rock mass, } \\
\text { and the economic loss caused by instability is greater }\end{array}$ \\
\hline W5 & Toppling & 3312 & Understable & $\begin{array}{l}\text { Houses, cultivated field, } \\
\text { roads }\end{array}$ & $\begin{array}{l}\text { The dangerous rock mass is far away from the house, and } \\
\text { the economic loss caused by instability is not large }\end{array}$ \\
\hline W6 & Falling & 2550 & Unstable & Cultivated field, road & The economic loss caused is not big \\
\hline
\end{tabular}

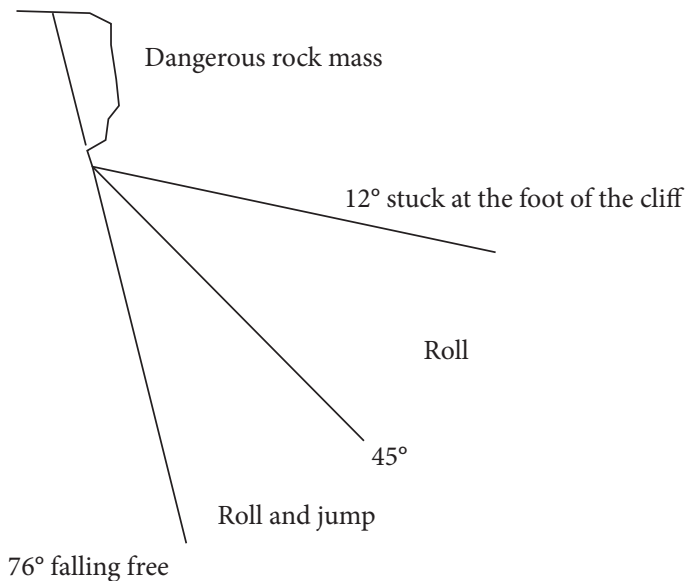

(a)

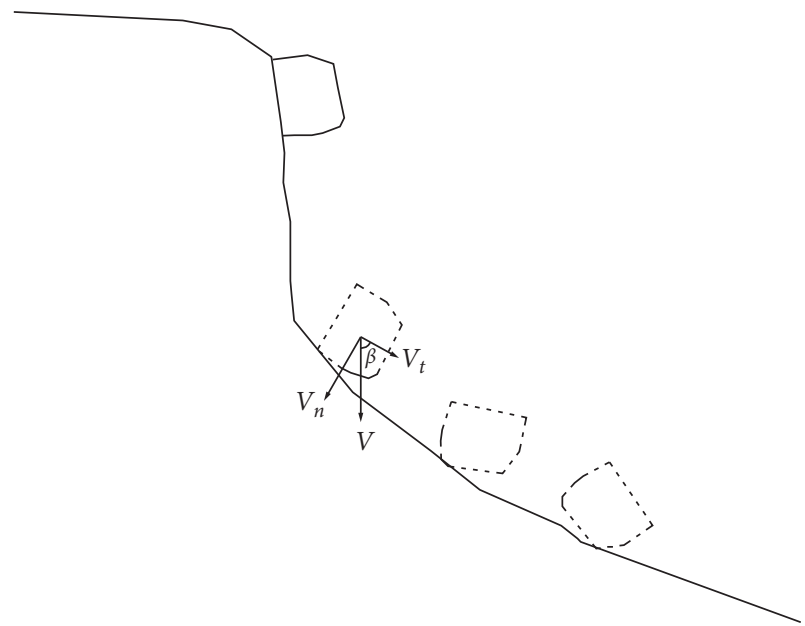

(b)

Figure 4: (a) Schematic diagram of the collapse and destruction movement of dangerous rocks. (b) The trajectory of dangerous rock collapse.

steep slopes. It stimulates the movement path, energy distribution, and bounce height changes of falling rocks on the slope by inputting basic parameters related to the slope and falling rocks. This software regards falling rocks as rigid mass points and the slope surface as isotropic plastic bodies, ignoring air resistance. The main parameters include the normal recovery coefficient, tangential recovery coefficient, dynamic friction coefficient, and the weight of the falling rock $[28,29]$. The slope restitution coefficient range used in the numerical simulation is shown in Table 5.

Dangerous rock mass located on a high slope has a lot of potential energy; according to the law of potential energy, the heavier the dangerous rock mass, the greater the potential energy. If they are unable to maintain their stability due to some reasons like external forces, or due to weathering, earthquakes, these dangerous rock masses will lose their stability and fall from the mountain [30].

In the process of falling dangerous rock mass, according to the law of conservation of kinetic energy, the huge potential energy of dangerous rock mass itself will be transformed into the kinetic energy of movement of dangerous rock mass [31]. The falling rock will collide with the slope body and consume part of the kinetic energy, because the normal recovery coefficient, tangential recovery coefficient, and inclination angle are different on different slopes [32].

When the rock falls to the bottom of the cliff, it collides with the gentle slope. After several jumps, most of the kinetic energy is consumed, and the rock begins to roll and slide into the gentle slope. Finally, with the kinetic energy under the action of the friction force of the gentle slope, the kinetic energy of the rock is consumed and the rock finally stops moving. Due to the difference in slope, friction coefficient and weight of falling rocks, the movement trajectory of falling rocks is also different, but in this process, the law of conservation of kinetic energy is still observed [33].

Numerical simulation software RocFall can directly analyze the trajectory of falling rock, which divides the 


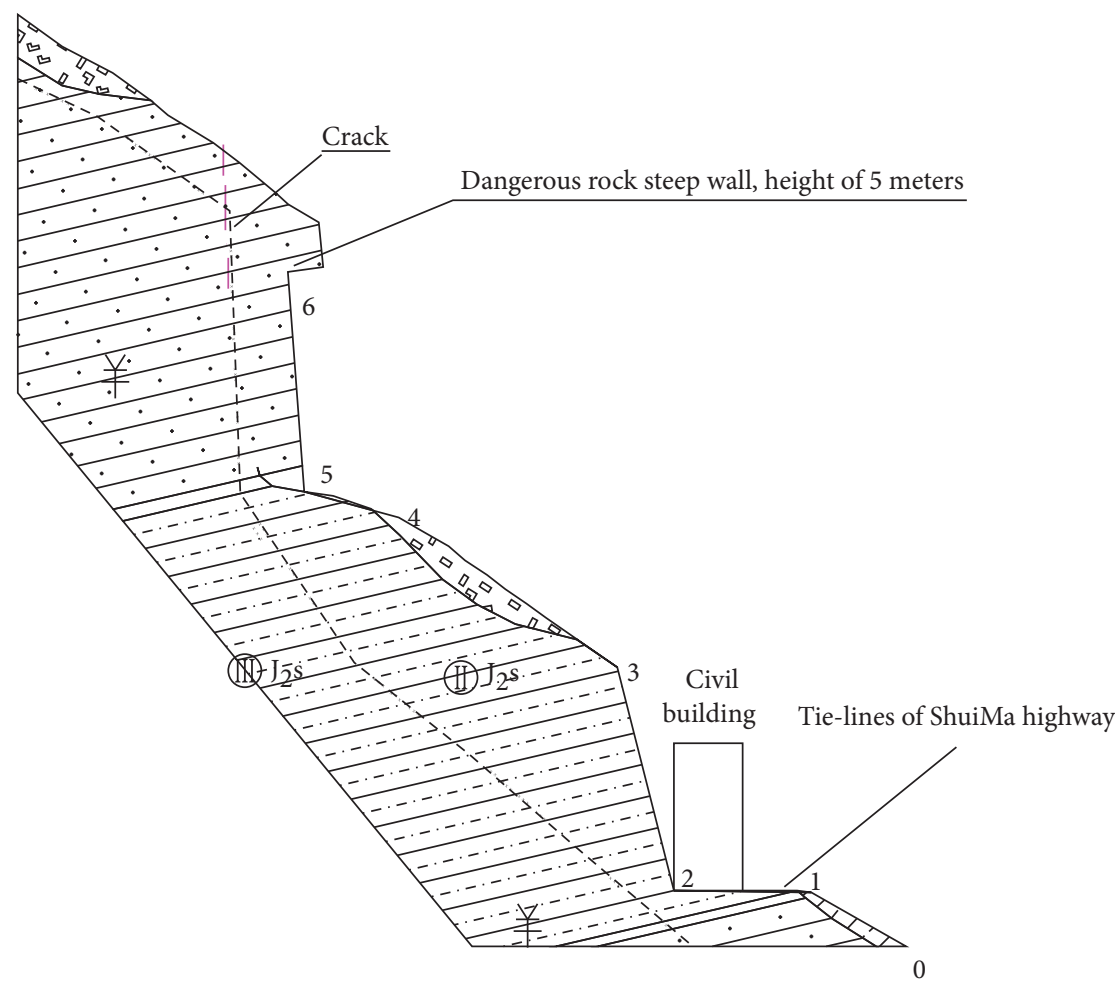

Rock and soil mass

Sandstone

Silty mudstone
J2s Middle Jurassic Shaximiao Formation 므 Structure

Lower boundary of strong $\sim$ moderately weathered rock

Figure 5: Geological section of dangerous rock mass W1.

TABLe 3: Maximum horizontal movement distance of dangerous rock mass.

\begin{tabular}{lcc}
\hline Dangerous rock mass number & Destruction mode & Horizontal movement distance $X(\mathrm{~m})$ \\
\hline W1 & & 52.91 \\
W3 & Falling & 57.99 \\
W4 & & 84.85 \\
W6 & \multirow{2}{*}{ Toppling } & 52.49 \\
W2 & & 61.25 \\
W5 & & 66.61 \\
\hline
\end{tabular}

TABLE 4: Calculation results of the jumping height of dangerous rock mass.

\begin{tabular}{lccc}
\hline Serial number & Jump safety value $h_{s}(\mathrm{~m})$ & Jumping height $h_{\max }(\mathrm{m})$ & Total high jump $h(\mathrm{~m})$ \\
\hline W1 & 1 & 8.964 & 9.964 \\
W2 & 1 & 2.697 & 3.697 \\
W3 & 1 & 7.133 & 8.133 \\
W4 & 1 & 17.930 & 18.930 \\
\hline
\end{tabular}


TABle 5: Range of restitution coefficient (according to Chen et al. [27]).

\begin{tabular}{lcc}
\hline Slope characteristics & $R n$ (normal recovery coefficient) & $\begin{array}{c}R t \text { (tangential recovery } \\
\text { coefficient) }\end{array}$ \\
\hline Smooth hard rock surface, paved concrete surface & $0.25 \sim 0.75$ & $0.88 \sim 0.98$ \\
Soft rock face, strong weathered hard rock face & $0.15 \sim 0.37$ & $0.78 \sim 0.95$ \\
Rock pile slope & $0.15 \sim 0.37$ & $0.75 \sim 0.95$ \\
Rubble dense, hard surface slope, the vegetation growth, to shrub & $0.12 \sim 0.33$ & $0.30 \sim 0.95$ \\
Dense gravel pile, hard soil slope, no or little vegetation development & $0.12 \sim 0.32$ & $0.65 \sim 0.95$ \\
Loose gravel piles, soft soil slopes, well-developed vegetation, mainly shrubs & $0.10 \sim 0.25$ & $0.30 \sim 0.80$ \\
Soft soil slope, no or little vegetation development & $0.10 \sim 0.30$ & $0.50 \sim 0.80$ \\
\hline
\end{tabular}

trajectory of falling rock into two processes: parabolic motion in the air and impact motion between falling rock and ground [34].

The equation of parabolic motion:

$$
\left(\frac{1}{2} g\right) t^{2}+\left(V_{Y_{0}}-q V_{X_{0}}\right) t+\left[Y_{0}-Y_{1}+q\left(X_{1}-X_{0}\right)\right]=0,
$$

$$
q=\frac{Y_{2}-Y_{1}}{X_{2}-X_{1}}
$$

where $X_{1}, Y_{1}$ represent the starting point coordinate of the straight line segment $(\mathrm{m}), \mathrm{g}$ is the acceleration of gravity $(\mathrm{m} /$ $\mathrm{s}^{2}$ ), and $V_{X 0}, V_{Y 0}$ are the fall velocity of rock $(\mathrm{m} / \mathrm{s})$, generally taking 0 .

Impact time equation:

$$
t=\frac{-b+\sqrt{b^{2}-4 a c}}{2 a},
$$

where $a=g / 2, b=V_{Y_{0}}-q V_{X_{0}}, c=Y_{0}-Y_{1}+q\left(X_{1}-X_{0}\right)$.

4.2. Numerical Simulation of the Motion Trajectory of the Falling Rock. When using RocFall software, we should first clarify the location, initial speed, and mass of the falling rock. Secondly, the two-dimensional model of the slope should be drawn according to a certain scale.

4.2.1. Determine the Initial State of the Falling Rock. In this simulation, without considering the influence of random factors, it is considered that when the rock mass leaves the ground, it is a free-fall motion with an initial velocity of zero. Regardless of the shape and size of the rock, treat it as a mass point.

4.2.2. Determine the Mechanical Parameters of the Slope. The rock will be affected by the slope friction during the falling process. During this process, the speed attenuation depends on parameters such as $R_{n}$ (normal recovery coefficient) and $R_{t}$ (tangential recovery coefficient). Table 6 lists the reference values of $R_{n}$ and $R_{t}$ for different geological slopes.
4.3. Simulation Calculation of the Falling Rock Trajectory. On the slope section where the dangerous rock is unstable, it is assumed that the near-spherical falling rock of the dangerous rock mass starts to move, and it moves in a combination of rolling, collision, bounce, and air flight.

Usually, the falling rock first falls freely, dumps and falls, then collides and rebounds or rolls down along the slope, rolls to the edge of the cliff, enters the next level of cliff, and continues to roll down until it stops or does projectile motion, or flies in the air, does projectile movement, and then collides again. Repeat this until it stops.

The independent motion simulations of 60 groups of single rolling rocks are performed randomly and the results are statistically analyzed to determine the most dangerous rolling rocks stagnation zone and maximum bouncing height. Through this numerical simulation, the results we want to obtain are the following items: the motion trajectory diagram of dangerous rock mass displayed in Figure 6. The bounce height envelope diagram of the dangerous rock mass is shown in Figure 7. The horizontal location of rock endpoints is shown in Figure 8.

The figure lists the parameters of each slope, the $X$ coordinate represents the relative horizontal distance between the falling rock and the instability point B.

$\mathrm{W} 1$ falls freely from point $\mathrm{B}$, most of the falling rocks hit section D-E, and they begin to roll and fall into section F-G and continue to bounce. Eventually, they stop at $X=53.93 \mathrm{~m}$. W2 falls freely from point $B$, it begins to roll at section C-E, then falls into section F-G, and continues to bounce. Eventually, it stops at $X=65.33 \mathrm{~m}$. W3 falls freely from point $\mathrm{B}$, after the jumping movement of section C-D, it will fall into section D-F and begins to roll, and then it falls into section G-H. Finally, it stops at $X=57.03 \mathrm{~m}$. W4 falls freely from point $\mathrm{B}$, rolls along section $\mathrm{C}-\mathrm{E}$, then falls into section F-G, and finally stops at $X=86.27 \mathrm{~m}$.

It can be seen that the shape of the slope is an important factor that affects the trajectory of falling rock. When the slope remains the same and the height increases, the potential energy of the rock is greater. After being converted into kinetic energy, the speed also increases. Its horizontal movement distance will be farther. In addition, due to the existence of the platform, the falling rock with a certain speed produces a greater bounce height.

As shown in Figure 7, the maximum bounce height of $\mathrm{W} 1$ is $9.68 \mathrm{~m}$, and the horizontal movement distance at this 
TABLE 6: Reference values of different geological slope sections $[35,36]$.

\begin{tabular}{lccc}
\hline Slope section of lithology & $R_{n}$ & $R_{t}$ & Coefficient of rolling friction \\
\hline The bedrock is exposed, the strong weathering sandstone, the rock quality is hard & 0.53 & 0.99 & 0.4 \\
The bedrock is exposed and strongly weathered mudstone & 0.3 & 0.86 & 0.48 \\
Weeds and shrubs covered by dense gravel piles, hard soil slope & 0.25 & 0.84 & 0.58 \\
Gravel soil and blocks of stone piled up & 0.28 & 0.85 & 0.4 \\
Loose gravel slope, soft soil slope & 0.2 & 0.61 & 0.54 \\
\hline
\end{tabular}

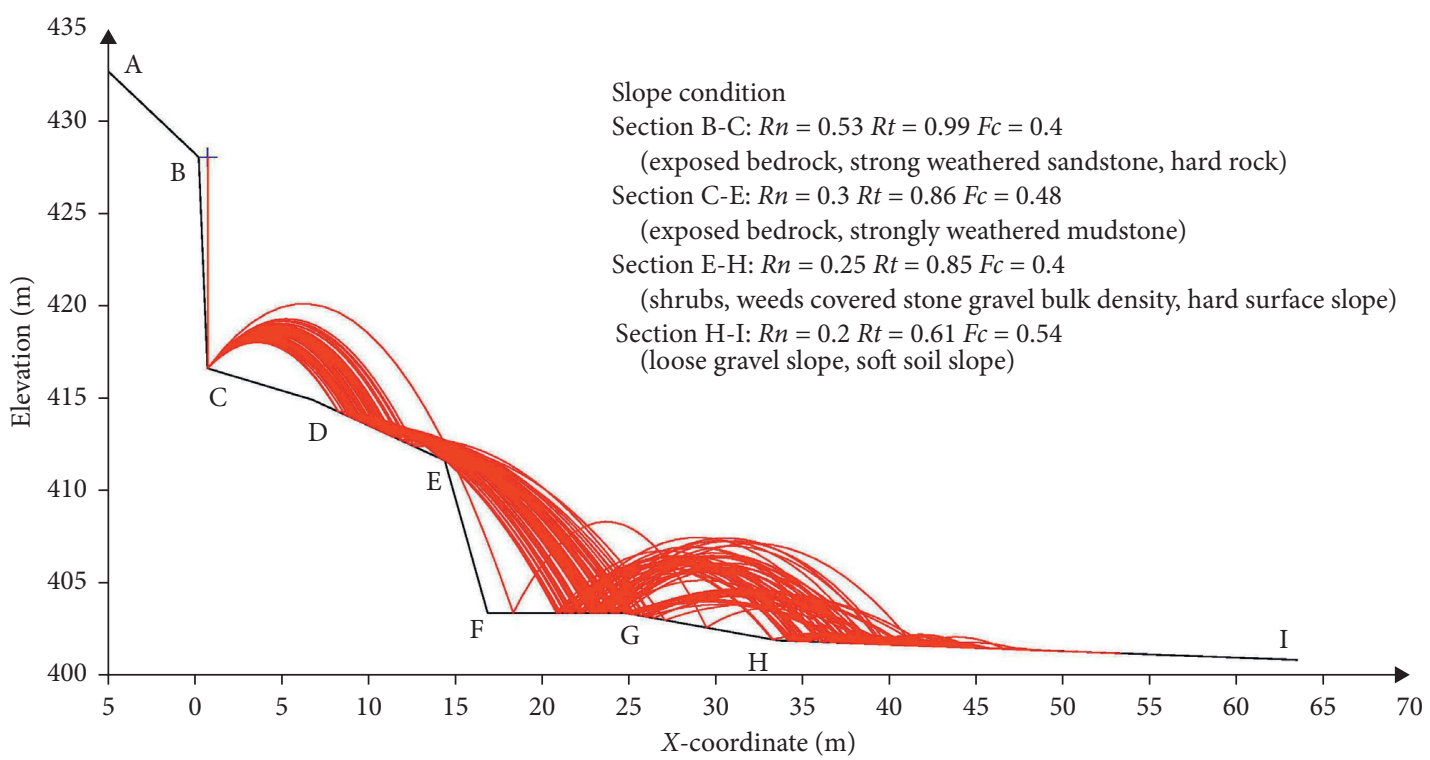

(a)

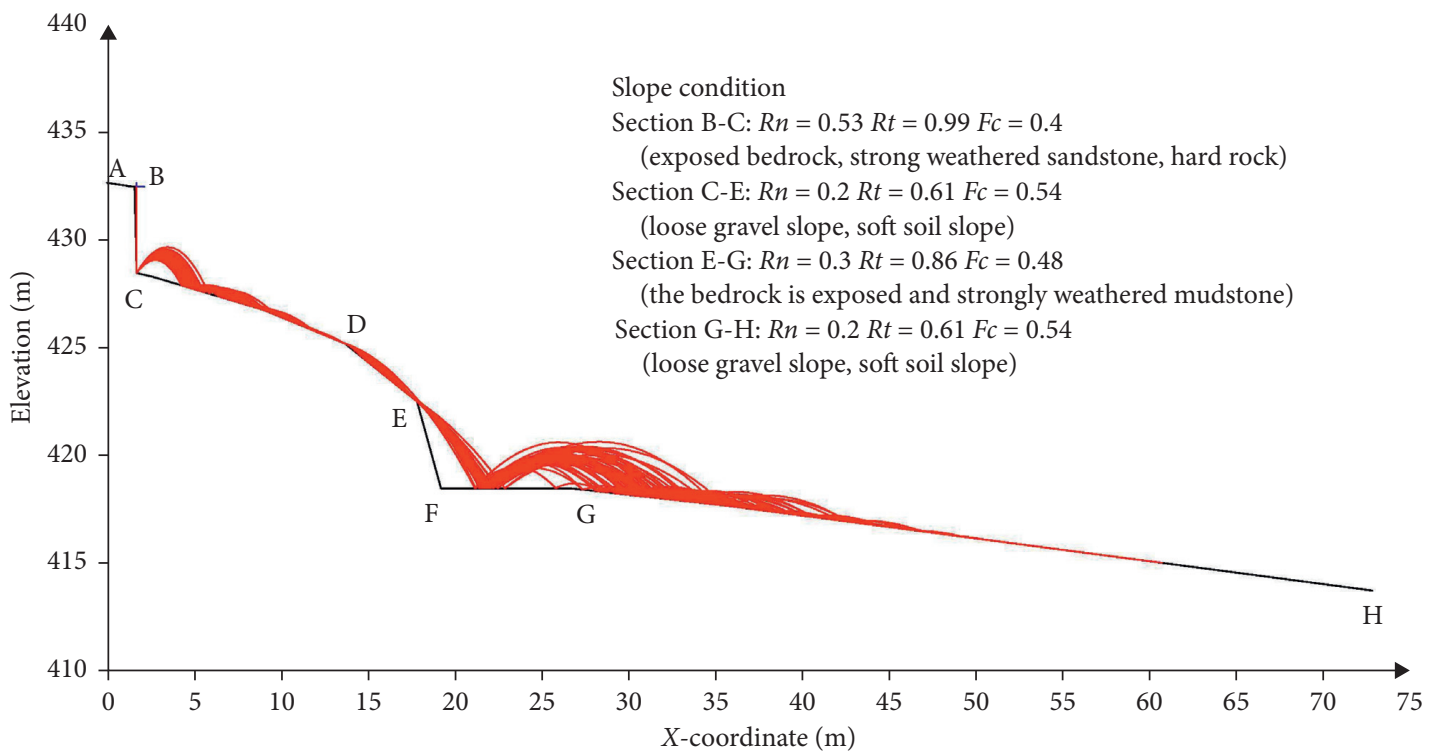

(b)

Figure 6: Continued. 


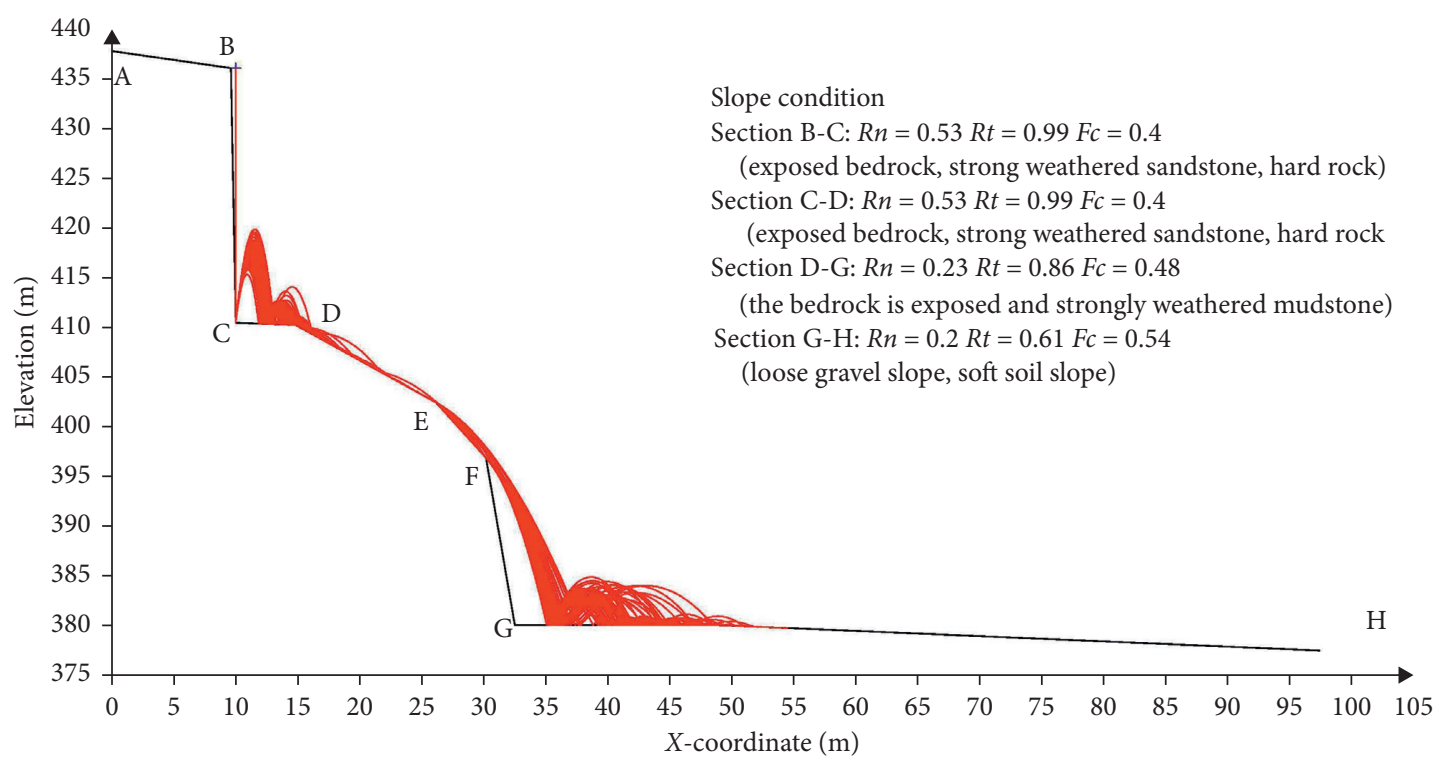

(c)

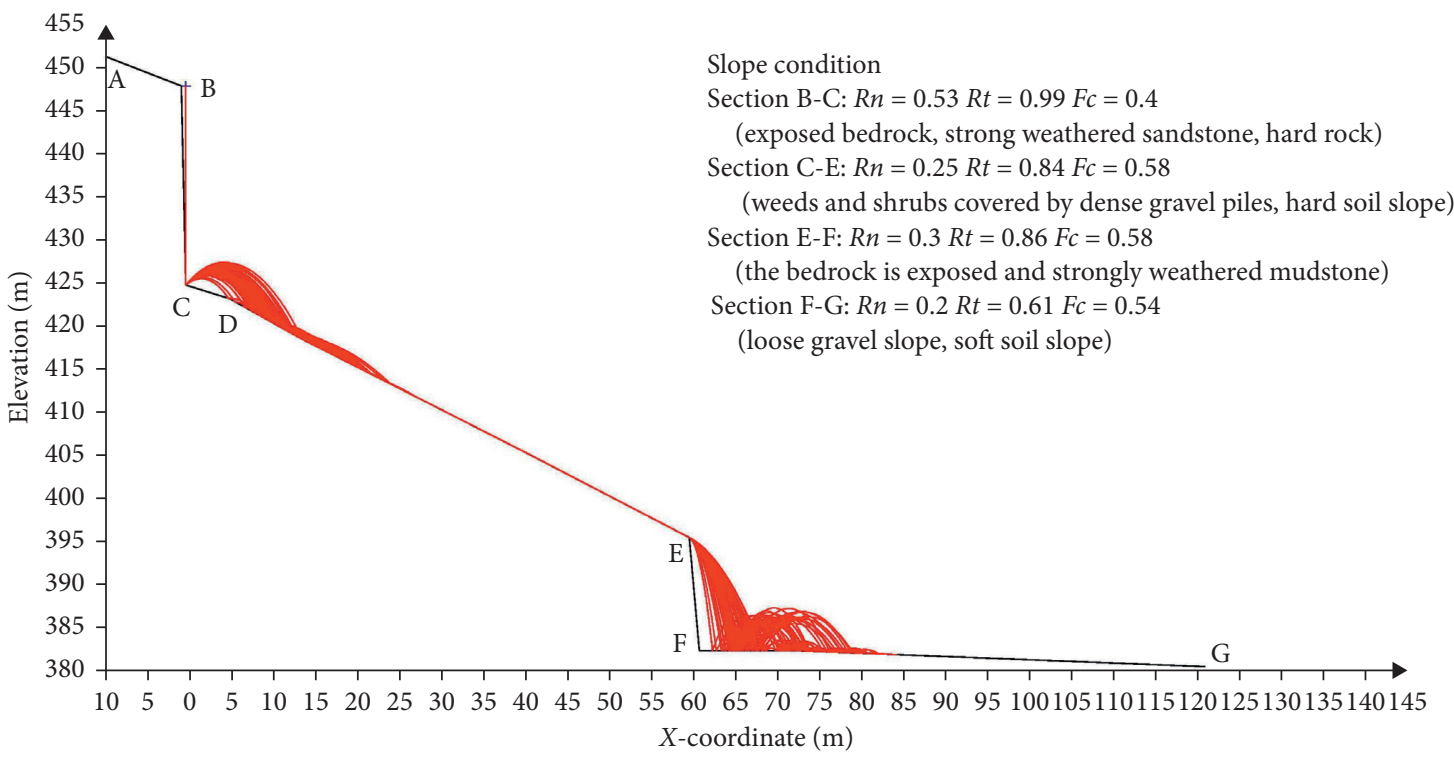

(d)

Figure 6: Motion trajectory diagram of the dangerous rock mass. (a) Motion trajectory diagram of W1. (b) Motion trajectory diagram of W2. (c) Motion trajectory diagram of W3. (d) Motion trajectory diagram of W4.

time is $19.13 \mathrm{~m}$, which is located in section F-G. The maximum bounce height of W2 is $3.71 \mathrm{~m}$, and the horizontal movement distance at this time is $20.59 \mathrm{~m}$, which is located in section F-G. The maximum bounce height of $\mathrm{W} 3$ is $8.13 \mathrm{~m}$, and the horizontal movement distance at this time is $34.22 \mathrm{~m}$, which is located in section G-H. The maximum bounce height of W4 is $18.86 \mathrm{~m}$, and the horizontal movement distance at this time is $62.18 \mathrm{~m}$, which is located in section F-G.
As shown in Figure 8, the farthest horizontal movement distance from $\mathrm{W} 1$ dangerous rock masses is $53.93 \mathrm{~m}$, and the falling rocks are mainly distributed at coordinates $37.5 \sim 48 \mathrm{~m}$. The farthest horizontal movement distance of W2 dangerous rock masses is $65.33 \mathrm{~m}$, and the falling rocks are mainly distributed at coordinates $41.3 \sim 63.8 \mathrm{~m}$. The farthest horizontal distance of W3 dangerous rock masses is $57.84 \mathrm{~m}$, and the falling rocks are mainly distributed at coordinates $44.8 \sim 58.8 \mathrm{~m}$. The farthest horizontal distance of 


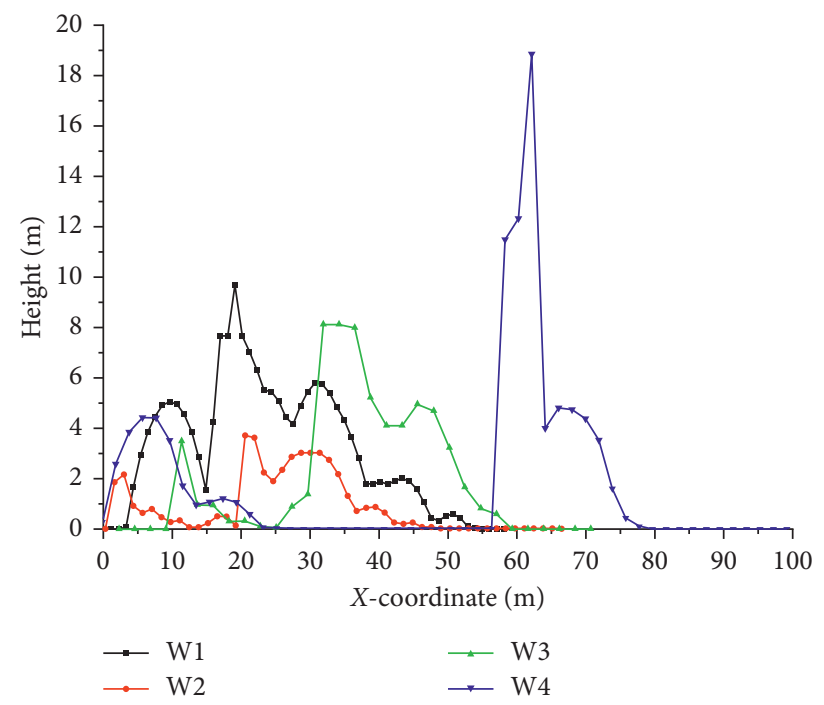

FIgURE 7: Bounce height envelope diagram of the dangerous rock mass.

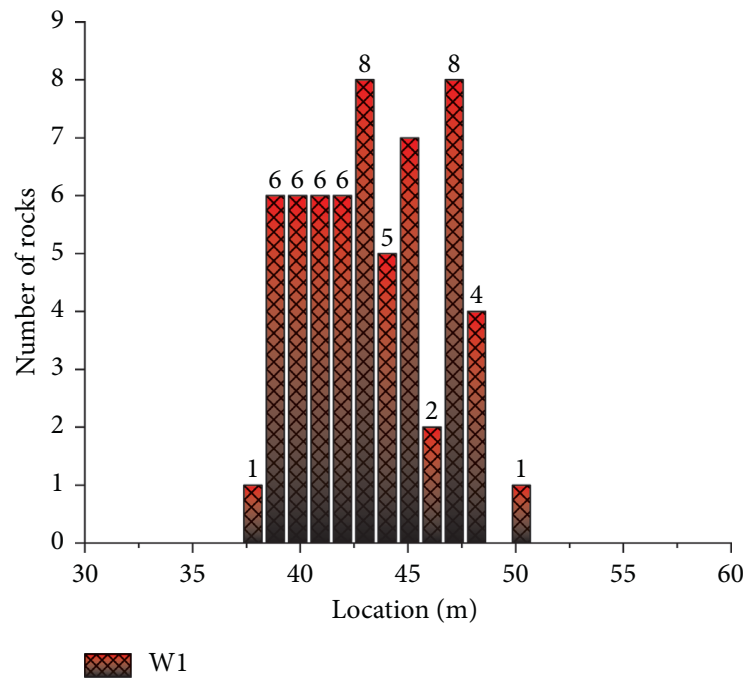

(a)

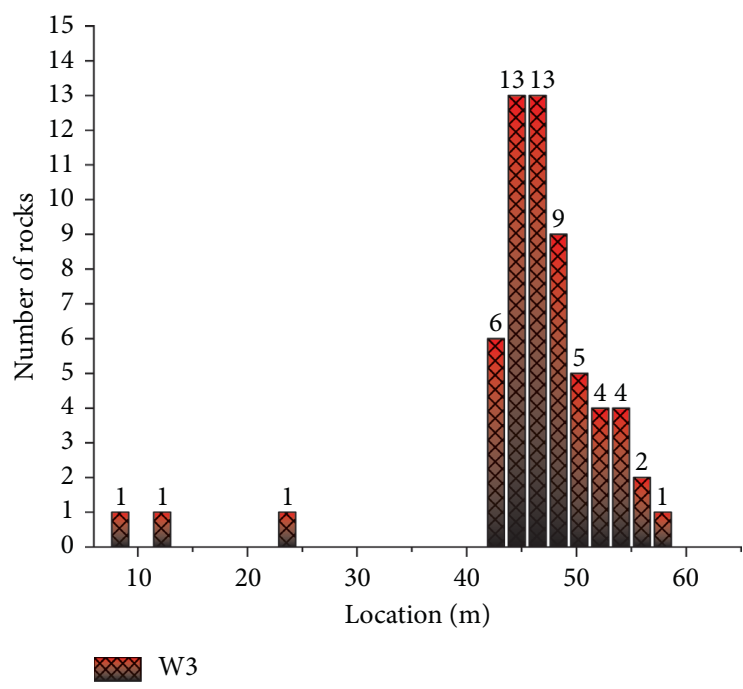

(c)

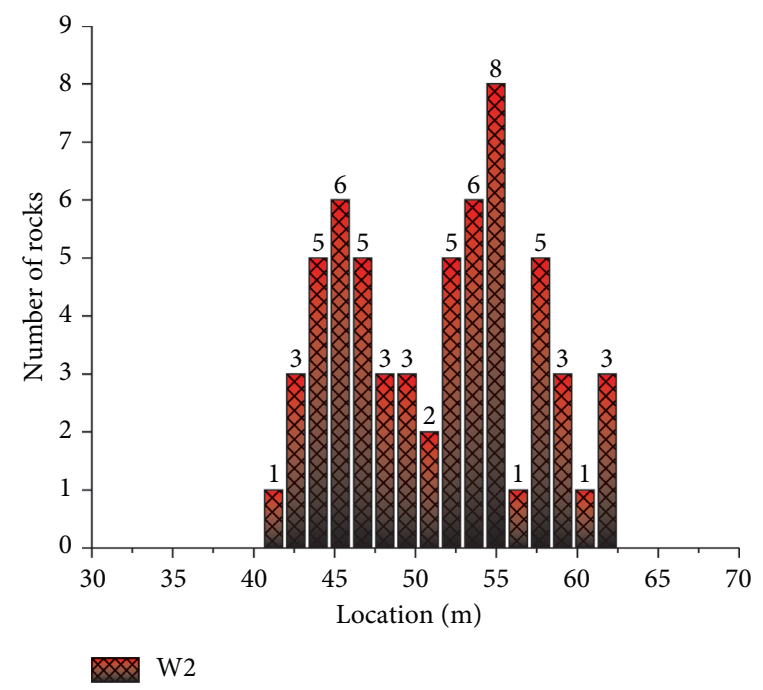

(b)

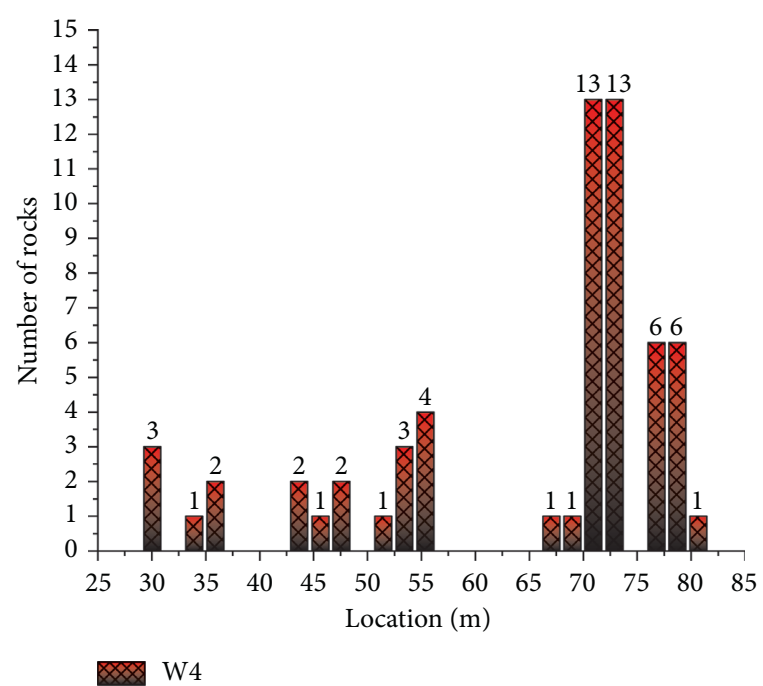

(d)

FIGURE 8: Horizontal location of rock end-points. (a) Rockfall distribution of W1. (b) Rockfall distribution of W2. (c) Rockfall distribution of W3. (d) Rockfall distribution of W4. 
TABLE 7: Comparison of results of two calculation methods of motion trajectory.

\begin{tabular}{lcccc}
\hline & \multicolumn{2}{c}{ Calculation method } & \multicolumn{2}{c}{$\begin{array}{c}\text { RocFall simulation } \\
\text { Serial } \\
\text { number }\end{array}$} \\
& $\begin{array}{c}\text { The formula to calculate } \\
\text { Horizontal distance } X \\
(\mathrm{~m})\end{array}$ & $\begin{array}{c}\text { Maximum bounce height of falling } \\
\text { rocks } H(\mathrm{~m})\end{array}$ & $\begin{array}{c}\text { Horizontal distance } X \\
(\mathrm{~m})\end{array}$ & $\begin{array}{c}\text { Maximum bounce height of falling } \\
\text { rocks } H(\mathrm{~m})\end{array}$ \\
\hline W1 & 52.91 & 9.96 & 53.93 & 9.682 \\
W2 & 61.25 & 3.70 & 65.33 & 3.714 \\
W3 & 57.99 & 8.13 & 57.03 & 8.135 \\
W4 & 84.85 & 18.93 & 86.27 & 18.863 \\
\hline
\end{tabular}

W4 dangerous rock masses is $86.27 \mathrm{~m}$, and the falling rocks are mainly distributed at coordinates $70.1 \sim 81.3 \mathrm{~m}$.

4.4. Analysis of Calculation Results. Comparing the calculation result with the RocFall software simulation result, it is found that the two results are relatively close. It can be seen from Table 7 that the results of calculating the trajectory of the dangerous rock mass by the two methods are not much different, indicating that the RocFall simulation can be used as a reference from the prediction of the trajectory of the dangerous rock mass.

\section{Risk Evaluation of Dangerous Rock Mass}

Pu'erdu Town was built close to the mountain. The instability of dangerous rock is a great threat to the safety of people or property. According to geological survey data, the total volume of collapsed and dangerous cliffs in the study area is $893,300 \mathrm{~m}^{3}$. The threats are mainly residents, streets, bridges, and so forth. Once the dangerous rocks become collapse, they will seriously threaten the lives of 2,685 people below and cause economic damage. The loss was as high as 120 million RMB Yuan. At present, the cliff rock is basically in an unstable state. Therefore, it is necessary to evaluate the instability risk of dangerous rock mass and provide data support for disaster prevention and mitigation in the study area. In this paper, risk assessment of dangerous rock mass of high slope is carried out from two aspects of risk and vulnerability.

5.1. Risk Assessment of Dangerous Rock Mass. According to the scale and stability of dangerous rock masses, the risk levels are classified, which is the semiquantitative method. The risk of dangerous rock mass is classified according to technical requirements for geological hazard evaluation of construction land, as shown in Table 8.

When categorizing the risk of dangerous rock masses, it is necessary to make a comprehensive judgment based on factors such as its scale, stability, instability failure type, and topography. The danger grade in dangerous rock mass in the study area is divided, and the results are as follows: I level dangerous rock mass: W3, W6; II level dangerous rock mass: W1, W4, W5; III level dangerous rock mass: W2.

5.2. Vulnerability Evaluation of Dangerous Rock Mass. Analyzing the damage degree of hazard-bearing bodies after the collapse of rock is the vulnerability evaluation of dangerous rock mass, which is an indispensable factor to study
TABLE 8: Hazard source level of the dangerous rock mass.

\begin{tabular}{lccc}
\hline Steady state & $\begin{array}{c}\text { Large scale } \\
\left(\geq 100 \mathrm{~m}^{3}\right)\end{array}$ & $\begin{array}{c}\text { Medium scale } \\
\left(10 \sim 100 \mathrm{~m}^{3}\right)\end{array}$ & $\begin{array}{c}\text { Small scale } \\
\left(<10 \mathrm{~m}^{3}\right)\end{array}$ \\
\hline Basically stable & III & III & III \\
Less stable & II & II & III \\
Unstable & I & I & I \\
\hline
\end{tabular}

the instability risk of the dangerous rock mass. The vulnerability evaluation is mainly to count the types, quantity, and loss value of the hazard-bearing bodies within the range of collapse threat of dangerous rock mass. The unstable dangerous rock mass may produce many different disasters bearing bodies, especially near the market town. In this paper, different hazard-bearing bodies were classified into the following four categories for statistics, as shown in Table 9.

The paper divides the severity of the losses suffered by the above four types of disaster-bearing bodies into three levels: mild, moderate, and severe. The degree of injury received by people is expressed as a minor injury, severe injury, and death. Combining the historical damage caused by the collapse of dangerous rock masses and the disaster resistance capacity of the disaster-bearing bodies of the study area, the vulnerability is classified into 3 levels in total. Aiming to quantitatively analyze the vulnerability of hazard-bearing bodies of the study area, a dimensionless assignment was made to the levels. The results are shown in Table 10.

According to the plan of the study area, the vulnerability evaluation of dangerous rock mass disaster in the study area is carried out, and the results are as follows: I level vulnerability: W1, W2, W3; II level vulnerability: W4; III level vulnerability: W5, W6.

5.3. Instability Risk Estimation of Dangerous Rock Mass. As the United Nations' definitions and formulas for geological hazard risk evaluation [37] to assess the risk of dangerous rock masses, the formula is as follows:

$$
R=H V=\left(\begin{array}{lll}
1 & 2 & 3
\end{array}\right)\left(\begin{array}{l}
3 \\
2 \\
1
\end{array}\right)=\left(\begin{array}{lll}
3 & 2 & 1 \\
6 & 4 & 2 \\
9 & 6 & 3
\end{array}\right)
$$

where $R$ is the risk index of dangerous rock mass, $H$ is the hazard score of the dangerous rock mass, and $V$ is the 
TABLE 9: Type of disaster-bearing body.

\begin{tabular}{lcc}
\hline Serial number & Type & Possible damage \\
\hline 1 & People & Injuries, deaths \\
2 & Arable land & Destroyed, buried \\
3 & Housing, engineering facilities & Collapse, cracking \\
4 & Highway & Damaged \\
\hline
\end{tabular}

TABLE 10: Vulnerability grade of disaster-bearing body.

\begin{tabular}{|c|c|c|c|}
\hline Level & Grade & Consequences & Score \\
\hline I & Severe & $\begin{array}{c}\text { A small number of people died or a large number of people were seriously injured, and the damage to property } \\
\text { was huge }\end{array}$ & 3 \\
\hline II & Moderate & A small number of serious injuries or more minor injuries, resulting in partial property damage & 2 \\
\hline III & Mild & There were no or a few minor injuries and little property damage & 1 \\
\hline
\end{tabular}

TABLE 11: Failure risk evaluation matrix of dangerous rock mass.

\begin{tabular}{lccc}
\hline Score & Serious vulnerability & Moderate vulnerability & Slight vulnerability \\
\hline Small risk & 3 & 2 & 1 \\
Medium risk & 6 & 4 & 2 \\
High risk & 9 & 6 & 3 \\
\hline
\end{tabular}

TABLE 12: Risk grade of dangerous rock mass.

\begin{tabular}{lcc}
\hline Serial number & Risk level & Risk index \\
\hline I & High & $6 \leq R_{i} \leq 9$ \\
II & Medium & $3 \leq R_{i}<6$ \\
III & Low & $1 \leq R_{i}<3$ \\
\hline
\end{tabular}

TABLE 13: Risk grade of dangerous rock mass.

\begin{tabular}{lcccc}
\hline Dangerous rock number & Hazard score & Vulnerability score & Risk index & Risk classification \\
\hline W1 & 2 & 3 & 6 & High \\
W2 & 1 & 3 & 3 & Medium \\
W3 & 3 & 3 & 4 & High \\
W4 & 2 & 2 & 2 & Medium \\
W5 & 2 & 1 & 3 & Low \\
W6 & 3 & 1 & Medium \\
\hline
\end{tabular}

vulnerability score of the dangerous rock mass. After determining the two major factors of hazard and vulnerability of dangerous rock mass, a matrix is formed to evaluate the risk of dangerous rock mass with the hazard as the column and the vulnerability as the row. Among them, each value of the matrix is the risk index of dangerous rock mass disaster. Table 11 is the evaluation level of instability risk of the dangerous rock mass.

According to the calculation results, the instability risk of dangerous rock mass is classified according to Table 12 .

According to the risk classification and vulnerability classification of dangerous rock mass in the study area, the risk grade classification of rock was carried out, and the results are shown in Table 13.

\section{Conclusion}

Based on the study of the stability of the dangerous rock mass in the treatment area, this paper predicts the movement trajectory of rock after the collapse. Based on the RocFall simulation verification, the risk evaluation of dangerous rock masses is carried out, and the following conclusions are drawn: 
(1) Through the comparison of formula calculation and numerical simulation analysis, the furthest horizontal movement distance, bounce height, and main distribution range of falling rocks can be determined, and RocFall software has a good effect on the prediction of falling rocks trajectory.

(2) Through dimensionless assignment and risk assessment matrix, W1 and W3 can be determined as high-risk dangerous rock mass, W2, W4, and W6 are medium-risk rocks, W5 is the low-risk rock mass. It is suggested that a reasonable and scientific engineering treatment scheme should be put forward in combination with the collapse trajectory and risk assessment results of dangerous rock mass, to eliminate the hidden danger of dangerous rock mass in the high slope of the treatment area as soon as possible.

(3) The trajectory calculated by the calculation formula is more accurate and the calculation results are more reliable. However, the calculation process is more complex and requires more process geological parameters to be prepared for the early stage, which consumes a lot of manpower and material resources and leads to high cost. At the same time, simulation by Rockfall software is convenient as fewer parameters are needed.

With the current study, the calculation method of collapse motion trajectory of dangerous rock mass and risk evaluation theory are not perfect for the prevention and control of geological disasters. The calculation method used in this article is just an attempt. And the effectiveness still needs to be verified and improved by generations of engineers and technicians in future engineering examples.

\section{Data Availability}

The data used to support the findings of this study are included within the article.

\section{Conflicts of Interest}

The authors declare that there are no conflicts of interest regarding the publication of this paper.

\section{Acknowledgments}

This study was sponsored by the Kunming Prospecting Design Institute of China Nonferrous Metal Industry Co., Ltd. (Risk Assessment Method of Dangerous Rock High Slope in Northeast Yunnan Based on Engineering Geological Evolution) and the Talent Development Program of Kunming University of Science and Technology (no. KKSY201767034).

\section{References}

[1] M. Bobbert, P. Huijing, and G. Schenau, "Instantaneous torqueangular velocity relationships during jumping," Journal of Biomechanics, vol. 18, no. 6, p. 553, 1985.
[2] L. K. A. Dorren, "A review of rockfall mechanics and modelling approaches," Progress in Physical Geography: Earth and Environment, vol. 27, no. 1, pp. 69-87, 2003.

[3] S. Cui, X. Pei, and R. Huang, "Study on velocity characteristics of rolling stone on straight slope," Journal of Engineering Geology, vol. 21, no. 5, pp. 912-915, 2013.

[4] T. Z. Gu He and T. W. Wang, "Study on prediction method of rockfall trajectory," Railway Architecture, vol. 8, pp. 8-13, 1992.

[5] H. Q. Yang and X. P. Zhou, "New method for calculating rockfall trajectory of slope," Geotechnical Mechanics, vol. 11, pp. 3411-3416, 2009.

[6] F. J. Fu, Z. Jun Hong, Z. bin, and C. Yu Long, "Segmented cycle algorithm of rockfall trajectory of slope," Chinese Journal of Geological Hazards and Prevention, vol. 4, pp. 96-101, 2011.

[7] Q. Cheng and S. Su, "Characteristics of rolling slope movement in Wenchuan earthquake collapse," Rock and Soil Mechanics, vol. 35, no. 2, pp. 772-776, 2014.

[8] W. Douglas Stevens, Rocball: A Tool for Probabilistic Analysis, Design of Remote Measures and Prediction of Rockfalls, University of Toronto, Toronto, Canada, 1998.

[9] S. Ye, K. Li, and C. Lin, "A method for three-dimensional prediction and analysis of rockfall trajectory combined with characteristics of geotechnical materials," Chinese patent: cn111737871a, 2020.

[10] F. Qin, Y. Peng, K. Xiangzhen, and Z. Jinhua, "Three dimensional analysis method of rockfall trajectory with arbitrary shape on geotechnical slope," Chinese patent: cn112258643a, 2021.

[11] C. Zhong, "Rocfall is used to simulate the influence of slope topography on rockfall motion characteristics," China Metal Bulletin, vol. 8, pp. 148-150, 2020.

[12] H. Zhu, Z. Yang, L. Cheng, R. Luo, and Z. Liu, "Study on rockfall trajectory of dangerous rocks based on rocfall numerical simulation: a case study of a section of dangerous rocks in the three gorges reservoir area," Scientific and Technological Innovation, vol. 19, pp. 45-46, 2020.

[13] H. Jianqun, "Application of Rocfall software in engineering design of geological disaster prevention and control of collapse," Engineering Construction and Design, vol. 12, pp. 33-34, 2020.

[14] S. Zhang and Y. Luo, "Discussion on prevention and control method of boulder falling in high and steep building slope based on rocfall simulation," Guangdong Civil Engineering and Architecture, vol. 26, no. 2, pp. 54-63, 2019.

[15] C. Luo, Z. Xiang, and R. Chen, "Rockwall design based on Rocfall," Nonferrous Metal Design, vol. 45, no. 4, pp. 12-23, 2018.

[16] X. Fu, Q. Sheng, Y. Zhang, J. Chen, and X. Leng, "Extension of discontinuous deformations analysis method to simulate seismic response of large rock cavern complex," International Journal of Geomechanics (ASCE), vol. 17, no. 5, 2017.

[17] L. Wang, C. Yongfeng, and N. Xingxin, "Calculation and application of blasting force transport distance based on rocfall numerical simulation," Mining Research and Development, vol. 35, no. 4, pp. 8-11, 2015.

[18] X. Fu, Q. Sheng, H. Tang et al., "Seismic stability analysis of a rock block using the block theory and Newmark method," International Journal for Numerical and Analytical Methods in Geomechanics, vol. 43, no. 7, 2019.

[19] S. Zeng, "Application of rocfall software in the design of dangerous rock collapse," China Water Transport(Second Monthly), vol. 11, no. 1, pp. 211-212, 2011. 
[20] J. Xu, M. Zhang, and W. Fan, "A review of geological hazard risk evaluation," Disaster, vol. 30, no. 4, pp. 130-134, 2015.

[21] X. Xiang and R. Huang, "Risk evaluation and risk management of geological hazards," Geological Hazards and Environmental protection, vol. 11, no. 1, pp. 38-41, 2000.

[22] Y. Han, P. Cui, and H. Liu, "Study on risk evaluation method and application of debris flow disaster," China Safety Science Journal, vol. 18, no. 12, pp. 141-147, 2008.

[23] M. Zhang, Geological Disaster of Landslide Collapse in Bota District of Yanan, Geological Publishing House, Beijing, China, 2008.

[24] J. RenQin, Stability Analysis and Treatment Method of Dangerous Rock in High Highway Slope in Chongqing Area, Chongqing Jiaotong University, Chongqing, China, 2014.

[25] J. Yuan and C. Fang, "Stability analysis and prevention of a dangerous rock belt in Chongqing," Western Exploration Project, vol. 5, pp. 121-124, 2008.

[26] S. Zeng, "Application of rocfall software in dangerous rock collapse treatment design," China Water Transport (second Half), vol. 11, no. 1, pp. 211-212, 2011.

[27] H. Chen, X. Xian, H. Tang, and L. Wang, "Stability analysis method of dangerous rock," Chinese Journal of Applied Mechanics, vol. 26, no. 2, pp. 278-407, 2009.

[28] C. Zhong, "Based on rocfall to simulate the influence of slope topography on the characteristics of falling rocks," China Metal Bulletin, vol. 8, pp. 148-150, 2020.

[29] H. Zhu, Z. Yang, L. Cheng, K. Luorong, and Z. Liu, "Research on the trajectory of dangerous rock caving based on rocfall numerical simulation-_taking a certain section of dangerous rock in the three gorges reservoir area as an example," Science and Technology Innovation, vol. 19, pp. 45-46, 2020.

[30] H. Jianqun, "Application of rocfall software in the design of geological collapse prevention and control engineering," Engineering Construction and Design, vol. 12, pp. 33-34, 2020.

[31] S. Zhang and Y. Luo, "Discussion on the prevention method of boulder roll-off on the slope of high and steep rock building based on rocfall simulation," Guangdong Civil Engineering and Construction, vol. 26, no. 2, pp. 54-63, 2019.

[32] C. Luo, Z. Xiang, and R. Chen, "Design of stone barrier based on rocfall," Nonferrous Metal Design, vol. 45, no. 4, pp. 12-23, 2018.

[33] Z. Lin, H. Wang, K. Gong, and G. Chen, "Research on the protection design of spherical weathered granite slope rolling rock disaster," Journal of Fuzhou University (Natural Science Edition), vol. 44, no. 5, pp. 760-766, 2016.

[34] C. Luo, X. Zhiqun, and C. Renquan, "Rock retaining wall design based on rocfall," Design of Nonferrous Metals, vol. 45, no. 4, pp. 12-23, 2018.

[35] S. Ye, H. Tang, and H. Zhu, "Design concept of rock-blocking net based on analysis of rockfall motion characteristics," Chinese Journal of Geotechnical Engineering, vol. 4, pp. 566571, 2007.

[36] X. Wang, L. Pai, and H. Wu, "Simulation analysis and experimental study on the failure of bridge structure caused by slope collapse and rock fall of Lalin railway," Chinese Journal of Rock Mechanics and Engineering, vol. 39, no. 8, pp. 1622$1633,2020$.

[37] United Nations. Department of Humanitarian Affects, Mitigating Natural Disasters: Phenomena, Effects and Options. A Manual for Policy Maker and Planners, United Nations, New York, NY, USA, 1991. 